and $610 \mathrm{~cm}^{-1}$, and these are three of the $e^{\prime}$ fundamentals. The fourth $e^{\prime}$ fundamental is the Raman frequency $162 \mathrm{~cm}^{-1}$, which is outside the infra-red region studied. In addition to this satisfactory correlation of the spectra it should be noted that although $-\mathrm{C} \equiv \mathrm{N}$ vibrations are always intense the infra-red spectrum most certainly contains only one $-\mathrm{C} \equiv \mathrm{N}$ frequency $\left(2,175 \mathrm{~cm}^{-1}\right)$ whereas the Raman spectrum contains two $\left(2,225\right.$ and $\left.2,175 \mathrm{~cm}^{-1}\right)$, and that the infra-red band is coincident with the depolarized Raman line. This pattern of $-\mathrm{C} \equiv \mathrm{N}$ frequencies is, in itself, strong evidence for the planar structure.

We thank Dr. W. O. George and Dr. D. Steele for help in obtaining infra-red spectra. One of us (R. A. G. C.) acknowledges leave of absence from Shell Research, Thornton, to work at Swansea.

$$
\begin{aligned}
& \text { D. A. Long } \\
& \text { R. A. G. Carrington } \\
& \text { R. B. Gravenor }
\end{aligned}
$$

Department of Chemistry,

University College of Swansea, Singleton Park, Swansea.

${ }^{1}$ Sehmidtmann, H., Ber., 29, 1171 (1896).

2 Middleton, W. J., Little, E. L., Coffmann, D. D., and Engelhardt, V. A,, J. Amer. Chem, Soc,, 80, 2795 (1958).

\section{Reactions of Sulphoxides with Phosphorus Compounds and Reactive Organic Halides}

Drmethyl sulphoxide is known as an oxidizing agent for organic halogen derivatives ${ }^{1}$ and certain aromatic methyl compounds ${ }^{2}$. Reactions of sulph. oxides with acid anhydrides give carboxylic acids and acyl derivatives of sulphides ${ }^{3}$. Organic sulphoxides have attracted attention as ligands in co-ordination compounds; but silicon halides and diphenyl sulphoxide give halogenated diphenyl sulphides and silicon oxychlorides and/or silica . Lappert and $\mathrm{Smith}^{5}$ investigated addition compounds of sulphoxides with boron, silicon, and tin halides, and reaction with boron trichloride or silicon tetrachloride gave a boron oxychloride-chloromethyl methyl sulphide addition compound, or silica and chloro-substituted sulphides.

Our work with phosphorus compounds and organic halides is summarized in equations (1-6).

$$
\begin{aligned}
& \mathrm{Ph}_{3} \mathrm{P}+\mathrm{Me}_{2} \mathrm{SO} \rightarrow \mathrm{Ph}_{3} \mathrm{PO}+\mathrm{Me}_{2} \mathrm{~S} \\
& \mathrm{Ph}_{2} \mathrm{PCl}+2 \mathrm{Me}_{2} \mathrm{SO} \rightarrow \mathrm{Ph}_{2} \mathrm{PO}_{2} \mathrm{H}+\mathrm{Me}_{2} \mathrm{~S}+ \\
& \mathrm{MeSCH}_{2} \mathrm{Cl} \\
& \mathrm{PhPCl}_{2}+3 \mathrm{Me}_{2} \mathrm{SO} \rightarrow \mathrm{PhPO}(\mathrm{OH})_{2}+\underset{\mathrm{Me}_{2} \mathrm{~S}+}{2 \mathrm{MeSCH}_{2} \mathrm{Cl}} \\
& \\
& \mathrm{N}_{3} \mathrm{P}_{3} \mathrm{Cl}_{6}+6 \mathrm{Me}_{2} \mathrm{SO} \rightarrow \mathrm{N}_{3} \mathrm{P}_{3} \mathrm{O}_{6} \mathrm{H}_{6}, \begin{array}{c}
\mathrm{MeSCH}_{2} \mathrm{Cl}+ \\
5 \mathrm{MeSCH}_{2} \mathrm{Cl}
\end{array} \\
& \mathrm{N}_{3} \mathrm{C}_{3} \mathrm{Cl}_{3}+3 \mathrm{Me}_{2} \mathrm{SO} \rightarrow \mathrm{N}_{3} \mathrm{C}_{3} \mathrm{O}_{3} \mathrm{H}_{3}+3 \mathrm{MeSCH}_{2} \mathrm{Cl} \\
& \mathrm{PhCOCl}+\mathrm{Me}_{2} \mathrm{SO} \rightarrow \mathrm{PhCO}_{2} \mathrm{H}+\mathrm{MeSCH}_{2} \mathrm{Cl}
\end{aligned}
$$

Dimethyl sulphoxide oxidizes certain tervalent phosphorus compounds to the quinquevalent state, when the by-product is dimethyl sulphide (1), or causes replacement of chlorine by hydroxyl in quinquevalent compounds, when chloromethyl methyl sulphide is formed (4). A combination of these processes is observed with diphenylchlorophosphine (2) and phenyldichlorophosphine (3). Hexachlorocyclotriphosphazatriene gives a moisture-sensitive chloromethyl methyl sulphide addition compound of the hydroxyoxophosphazane (4), and the product of a similar reaction with octachlorocyclotetraphosphazatetraene gives the dihydrate of tetrakis(hydroxyoxo)cyclotetraphosphazane $\theta^{6}$ on mild treatment with water.

Cyanuric chloride (5) and benzoyl chloride (6) are converted to cyanuric acid and benzoic acid respectively. It seems likely that this reaction will have wide applications to inorganic and organic compounds containing reactive halogen atoms.

Diphenyl sulphoxide is less reactive than dimethyl sulphoxide but the same pattern of behaviour is observed.

We thank the Agricultural Research Service of the U.S. Dopartment of Agriculture for financial support under Public Law 480.

\section{S. K. RAY}

R. A. SHAW

Department of Chemistry,

B. C. Sмгтн

Birkbeck College (University of London), London, W.C.1.

${ }^{1}$ Kornblum, N., Powers, J. W., Anderson, G. J., Jones, W. J., Larson, H. O., Levand, $\dot{o}_{\text {., }}$ and Weaver, W. M., J. Amer. "Chem. Soc., 79, 6562 (1957). Ǩrnblum, N., Jones, W. J., and Anderson, G. J., ibid., 91, 4113 (1959).

${ }^{2}$ Leitch, J., and Wessely, F., Monatsh., 93, 566 (1962).

'Horner, L., and Kaiser, P., Annalen, 626, 19 (1959); 631, 198 (1960).

- Issleib, K., and Tzschach, M., Z anorg. Chem., 305, 198 (1960).

- Lappert, M. F., and Smith, J. K., J. Chem. Soc., 3224 (1961).

- Shaw, R. A., Fitzsimmons, B. W., and Smith, B. C., Chem. Revs., 62, 247 (1962).

\section{Structures of Sepiapterin and Isosepiapterin}

SEPIAPTERIN and isosepiapterin are yellow, yellowfluorescent compounds which occur in Drosophila melanogaster and accumulate in the sepia mutant. They are believed to be closely related 2-amino-4-oxo6 -acyltetrahydropteridines, the acyl group in isosepiapterin being propionyl and in sepiapterin, lactyl. However, there has been some controversy concerning the location of the hydrogen atoms on the pyrazine part of the molecule. Forrest ${ }^{1}$ favoured a distribution of the hydrogens on the 5 and 8 positions largely by analogy with the yellow 5,8-dihydro compounds (for example, I) synthesized by Pfleiderer and Taylor' ${ }^{2}$, and with the 5,8-dihydro structure assigned to the red dihydroquinoxaline (II) on the basis of its nuclear magnetic resonance spectrum by Barltrop, Richards and Russell ${ }^{\circ}$.

Nawa 4 , on the other hand, considered the 7,8 dihydro structure more probable because of his

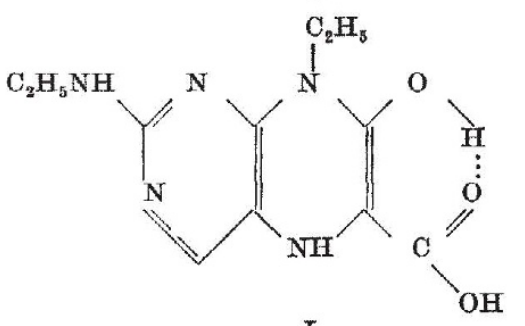

I

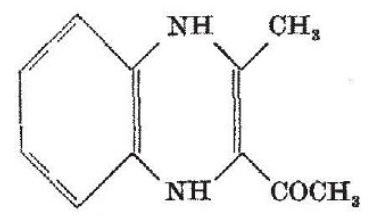

II 